\title{
Malaysian Water Utilities Performance Using Two-Stage DEA
}

\author{
Norbaizura Kamarudin ${ }^{1}$, Wan Rosmanira Ismail2, Muhammad Azri Mohd ${ }^{3}$ \\ ${ }^{1}$ Centre for Statistical and Decision Sciences Studies, Faculty of Computer and Mathematical Sciences, \\ Universiti Teknologi MARA, 40450 Shah Alam, Selangor DE, Malaysia. \\ ${ }^{2}$ School of Mathematical Sciences, Faculty of Science and Technology, Universiti Kebangsaan Malaysia, \\ 43600 UKM Bangi, Selangor DE, Malaysia. \\ ${ }^{3}$ Centre for Actuarial Studies, Faculty of Computer and Mathematical Sciences, Universiti Teknologi MARA, \\ 40450 Shah Alam, Selangor DE, Malaysia.
}

* Corresponding author. Tel.: +60355435471; email: norbaizura@tmsk.uitm.edu.my Manuscript submitted October 13, 2014; accepted January 4, 2015.

doi: 10.17706/ijapm.2015.5.1.60-66

\begin{abstract}
Most previous studies on the performance of water utility services have adopted the standard data envelopment analysis (DEA) with slight modification. However, there are some loopholes which they have neglected the internal structure of proper measures of the operating performance of water utilities. This study uses a two-stage DEA to measure the performance of water supply services in Malaysia. The first stage uses operating cost and other factors to sustain the water production in terms of length of pipes involved and the number of clients. While in the second stage, the water production will generate revenue due to water delivered or consumed by clients. The two stages are an integrated efficiency model where optimal performance can be measured for both stages at the same time. The model will forms efficiency breakdown for both individual stages and uniquely it provides informative comprehensions compared to the traditional DEA.
\end{abstract}

Key words: Data envelopment analysis, performance measurement, water utilities.

\section{Introduction}

Malaysia is an equatorial climates country, experience no dry seasons and it is typically hot and wet throughout the year. This country is flooded with both heavy and frequent rainfall exceeds $2600 \mathrm{~mm}$ per year. Most of the area is always cloudy and experience high humidity. Malaysia should be a country that rich in water resources, but the impact of the changing weather patterns as well as the dramatic increase in the population density of the urban and suburban make it more difficult to meet the demand of treated water.

Although this is a global crisis where water resources are usually far from the zone of high density demand, but thorough planning of water resources management must be implemented to prevent water shortage crisis. The cause of the water crisis is not only due to shrinking water resources, but also due to lack of planning and work force capable for comprehensive implementation. One of the measures for improvement is to enhance the performance of water supply services in the country. To make those improvements, first of all, the performance of existing Malaysian water supply services should be measured.

Under the Federal Constitution of Malaysia, the water supply services are the responsibility of the state government. Agencies under state governments either by the State Public Works Department (PWD), State Water Supply Department (WSD), or the State Water Supply Boardis responsible for the development, 
operation and maintenance of water supplies for every state in Malaysia. This study is intended to measure the performance of Malaysian states's water supply service by using a method based on Data Envelopment Analysis (DEA) model.

\section{Methodology}

According to Ramano and Guerrini [1], since the year of 1986, pioneered by Byrnes et al [2], there are a lot of studies worldwide have used DEA models involving the performance of the water industry [3]-[6]. Most of the studies have multi-output and employed input-oriented DEA technique and using CRS and VRSmodels [1]. The majority of researchers used similar input and output factors such as operational expenditure, number of employees, and /or length of the water main as input. While the volume of water delivered, billed or produced water, and a number of water connections represent the resident population were used as output. Furthermore, most of the research adopted a standard DEA method with some modification [1]-[6]. With some expansion on the standard model, it helps in reviewing the factors related to the industry's operating performance internally.

Additionally, studies as in [1]-[6] also measured performance of water utility as their decision-maker Units (DMUs) involving multiple inputs and outputs which are the factors related to the operating performance of water supply services.

Commonly in all examples, the evaluation of the DMUs always form a two-stage network structure and mutually have a same feature. This common feature is the intermediate measures whereby it is referred as an outputs from the first stage and it is used again, however as the inputs in the second stage [7].

\section{Data and Model}

Data for this study were obtained from the Malaysian Water Industry Guide 2013 [8], issued by the Malaysian Water Association (MWA). Data for water utility services in 14 states in Malaysia were available for 2011 and 2012. Based on the data available from [8], selected factors for inputs and outputs associated with the performance of water supply services are: operational cost (OPEX), number of employees, system input volume (SIV), number of connections, length of pipes, total revenue and billed authorized consumption. The choice of inputs and outputs for both stages is influenced by literatures on DEA applications in water supply services. Definition of factors selected for performance measurement are as follows:

Operation cost (OPEX) includes all variable resources expended to channel the treated water from the water treatment plants to the customers. A lower value indicates a more efficient water utility [9].

Number of connections, describe the number of supply connections conveyed by a company while the length of pipes reflects the dissemination of customers. These two variables are expected to have an impact on OPEX because they describe the scale size of the water distribution network [9].

Billed Authorized consumption represents the amount of water delivered, measured work done by utilities in supplying water and so it also will affect the OPEX level [9].

The number of employees represents the labor force for each of water utilities, whereas the system input volume (SIV) indicates the volume of producing water from treatment plants before the distribution process begins.

Total Revenue includes tariff and non tariff revenue generated from billed authorized consumption from customers.

Specifically for CCR model [10], total revenue, distributed water, the subsequent volume, number of connections and the length of the pipes are labelled as outputs in the water distribution business. The OPEX and number of employees are treated as inputs needed to produce the outputs. 


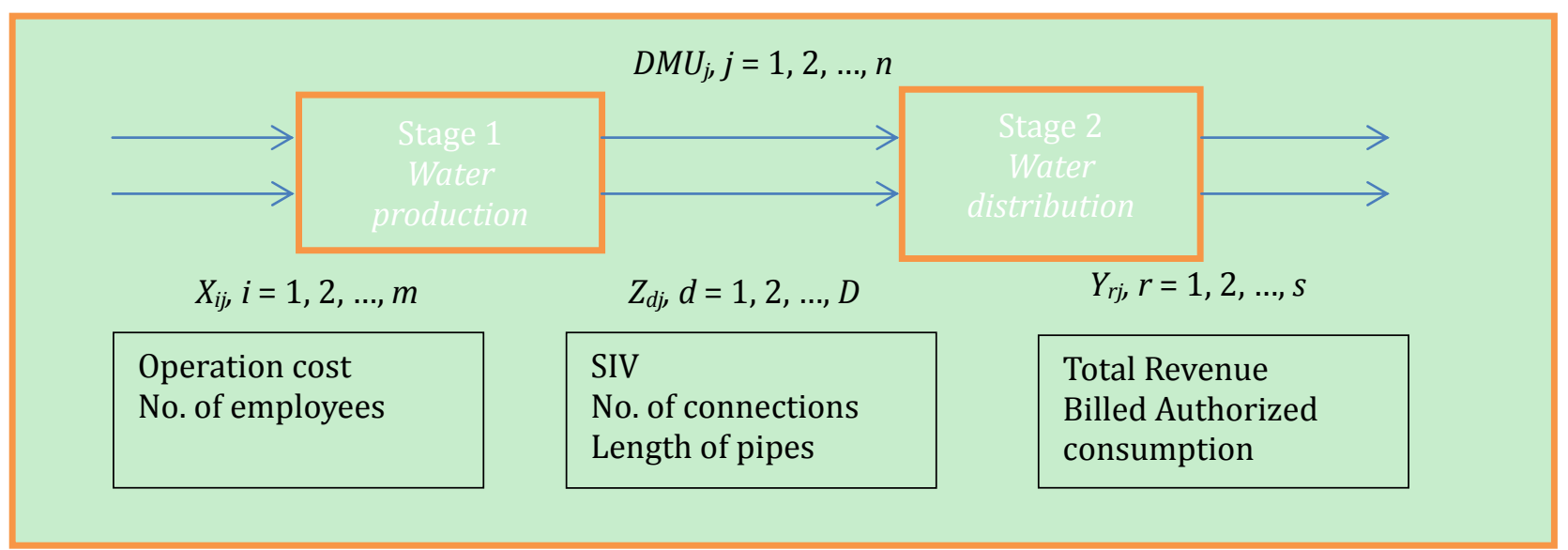

Fig. 1. Water utilities two-stage performance.

Nevertheless, based on the airlines' two-stage performance by Zhu [11], seven factors related to the performance of water supply services can be grouped as a two-stage operation, which are water production process and water distribution process as depicted in Fig. 1. The choice of inputs and outputs for both stages is influenced by literatures on DEA applications in water supply services.

Stage 1 is for a water production process where it engaged cost expenditure and number of employees as inputs to the outputs, namely the SIV, number of connections and the length of the pipes. The aim is to minimize the costs and usage of labors given the water production in terms of the number of connections and length of pipes involved. While in the second stage, the SIV, number of connections and length of pipes is used as resources in the water distribution process to generate revenues for the utilities and water delivered to the customers.

As shown in Fig. 1, SIV, number of connections, and length of pipes are treated as intermediate measures whose optimal values are determined via a centralized model. Liang et al. [12], introduced the centralized model which includes the notion for intermediate measure, assuming each $D M U_{j}, j=1,2, \ldots, n$ has $D$ intermediate measures $Z_{d j}, d=1,2, \ldots, D$. Based on [12], Zhu [11], converted the model to the linear program below:

$$
\begin{aligned}
& e_{o}^{\text {centralized }}=\operatorname{Max} \sum_{r=1}^{s} u_{r} y_{r o} \\
& \text { s.t. } \\
& \sum_{r=1}^{s} u_{r} y_{r j}-\sum_{d=1}^{D} w_{d} z_{d j} \leq 0, j=1,2, \ldots, n, \\
& \sum_{d=1}^{D} w_{d} z_{d j}-\sum_{i=1}^{m} v_{i} x_{i j} \leq 0, j=1,2, \ldots, n, \\
& \sum_{i=1}^{m} v_{i} x_{i o}=1, \\
& w_{d} \geq 0, d=1,2, \ldots, D ; v_{i} \geq 0, i=1,2, \ldots, m ; u_{r} \geq 0, r=1,2, \ldots, s .
\end{aligned}
$$

The overall efficiency of the two-stage process can be obtained by using model (1). While the efficiencies for the first and second stage can be obtained at the following model(2), with an assumption of the model (1) gives a unique solution. 


$$
e_{o}^{1, \text { Centralized }}=\frac{\sum_{d=1}^{D} w_{d}^{*} z_{d o}}{\sum_{i=1}^{m} v_{i}^{*} x_{i o}}=\sum_{d=1}^{D} w_{d}^{*} z_{d o} \quad \text { and } \quad e_{o}^{2, \text { Centralized }}=\frac{\sum_{r=1}^{s} u_{r}^{*} y_{r o}}{\sum_{d=1}^{D} w_{d}^{*} z_{d o}} .
$$

Furthermore, the optimal value of model (1) is denoted as $e_{o}^{\text {centralized }}$, whereit is equal to the multiplication of $e_{o}^{1, \text { Centralized }}$ and $e_{o}^{2, \text { Centralized }}$. Consequently, the optimal multipliers from model (1) may not be unique andthus $e_{o}^{1, \text { Centralized }}$ and $e_{o}^{2, \text { Centralized }}$ may also not be unique.

\section{Application}

In this study, we apply the same method as in Zhu [11] to measure the performance of 14 states as entities or utilities for water supply services in Malaysia. Firstly, we applied the standard CCR DEA model to the water utilities in 2011 and 2012 respectively. Table 1 shows the CCR efficiency scores for the year 2011 and 2012. Only five states are efficient in 2011, while 6 states are efficient for 2012. But most of other states show quite higher efficiency scores except for one state shows score less than $50 \%$ in each year.

Table 2 and Table 3 report the results from the model Table 1 and the efficiency decomposition based upon model Table 2. According to Chen et al. [13], when intermediate measures are exists, it is possible that none of the DMUs are efficient. In both years, four states which are Selangor, Terengganu, Pulau Pinang and Perak are among the top ranked based on overall centralized scores. Meanwhile, Kedah in 2011 has been defeated by Johor in 2012 as one of the top five highest overall scores.

\begin{tabular}{lcc}
\multicolumn{3}{l}{ Table 1. Standard CCR DEA Efficiency } \\
\hline \hline State & 2011 & 2012 \\
\hline Johor & 0.863 & 1 \\
Kedah & 0.949 & 0.911 \\
Kelantan & 0.861 & 1 \\
Labuan & 0.374 & 0.401 \\
Melaka & 0.773 & 0.783 \\
Negeri & & \\
Sembilan & 0.822 & 0.683 \\
Pulau Pinang & 1 & 0.958 \\
Pahang & 0.671 & 0.872 \\
Perak & 1 & 1 \\
Perlis & 1 & 1 \\
Sabah & 0.76 & 0.797 \\
Sarawak & 0.664 & 0.821 \\
Selangor & 1 & 1 \\
Terengganu & 1 & 1 \\
\hline \hline
\end{tabular}

In 2011, only Perlis and Terengganu achieved 100\% efficiency in the first stage of water production. While for second stage of water distribution, three states which are Labuan, Pulau Pinang and Selangor have achieved $100 \%$ efficiency. This result indicates most of the states are not efficient in both stages. Some states with high score in the first stage showed a lower score in the second stage and some are vice versa. Perlis is efficient in the first stage, but has the lowest score in second stage. While Labuan showed otherwise, lower score in water production (stage 1), but efficient in the water distributing process (stage 2). Even though the five efficient states (Selangor, Terengganu, Pulau Pinang, Perak and Perlis) in the standard DEA model are ranked very high under centralized scores except for Perlis. Note that Perlis is efficient under the standard DEA, but ranked quite low under centralized score. This result also indicates 
the standard DEA model does not measure some of the inefficiencies in these water utility operations. In fact Labuan has the lowest score in the standard DEA and centralized scores, but is efficient in the second stage. It shows Labuan is very efficient in the water distribution process (stage 2) while suppose to improve the efficiency in the water production process (stage 1).

Table 2. Centralized Results in 2011

\begin{tabular}{lcccc}
\hline \hline State & $\begin{array}{c}\text { Centralized } \\
\text { Efficiency } \\
\text { centralized }\end{array}$ & Rank & $e_{o}^{1, \text { Centralized }}$ & $e_{o}^{2, \text { Centralizec }}$ \\
& $e_{o}$ & & & \\
\hline Johor & 0.566 & 7 & 0.654 & 0.865 \\
Kedah & 0.615 & 5 & 0.939 & 0.655 \\
Kelantan & 0.377 & 12 & 0.683 & 0.551 \\
Labuan & 0.258 & 14 & 0.258 & 1.000 \\
Melaka & 0.590 & 6 & 0.639 & 0.923 \\
Negeri Sembilan & 0.531 & 8 & 0.770 & 0.689 \\
Pulau Pinang & 0.760 & 3 & 0.760 & 1.000 \\
Pahang & 0.362 & 13 & 0.650 & 0.557 \\
Perak & 0.719 & 4 & 0.848 & 0.847 \\
Perlis & 0.507 & 9 & 1.000 & 0.507 \\
Sabah & 0.469 & 10 & 0.737 & 0.637 \\
Sarawak & 0.410 & 11 & 0.471 & 0.871 \\
Selangor & 0.832 & 1 & 0.832 & 1.000 \\
Terengganu & 0.790 & 2 & 1.000 & 0.790 \\
\hline \hline
\end{tabular}

Table 3. Centralized Results in 2012

\begin{tabular}{lcccc}
\hline \hline State & $\begin{array}{c}\text { Centralized } \\
\text { Efficiency } \\
\text { centralized }\end{array}$ & Rank & $e_{o}^{1, \text { Centrali: }}$ & $e_{o}^{2, \text { Centralized }}$ \\
\hline Johor & 0.708 & 3 & 0.725 & 0.976 \\
Kedah & 0.519 & 7 & 0.829 & 0.625 \\
Kelantan & 0.360 & 13 & 0.706 & 0.510 \\
Labuan & 0.235 & 14 & 0.235 & 1.000 \\
Melaka & 0.538 & 6 & 0.620 & 0.867 \\
Negeri & & & & \\
Sembilan & 0.402 & 12 & 0.537 & 0.748 \\
Pulau Pinang & 0.653 & 5 & 0.653 & 1.000 \\
Pahang & 0.412 & 11 & 0.723 & 0.571 \\
Perak & 0.684 & 4 & 0.782 & 0.875 \\
Perlis & 0.419 & 10 & 1.000 & 0.419 \\
Sabah & 0.484 & 8 & 0.613 & 0.789 \\
Sarawak & 0.464 & 9 & 0.533 & 0.871 \\
Selangor & 0.753 & 1 & 0.753 & 1.000 \\
Terengganu & 0.766 & 0.980 & 0.781 \\
\hline \hline
\end{tabular}

Whereas in 2012, only Perlis remains 100\% efficiency for the first stage while in the second stage, the same three states as in 2011 remain efficient that is Labuan, Pulau Pinang and Selangor which maintain their efficiency in the water distribution process (stage 2). The result for centralized model is quite similar to the situation in 2011, where most of the states are not efficient in using their resources in the water production process. Note that Perlis and Labuan still have similar results as previously. Based on standard DEA results for 2012, Johor and Kelantan are efficient together with Perak, Perlis, Selangor and Terengganu which are also efficient in the previous year (2011). But under centralized scores, Kelantan has a lower ranking, compare to the rest of efficient states above. Johor has improved its efficiency in 2012 both under standard DEA model and under centralized model. While Labuan, still has the lowest performance among all. 
The result also shows that simply classifying all performance factors as inputs and outputs in the standard DEA model may not completely identify inefficiency in performance. As, for example, in both years, Perlis is efficient under the basic DEA model. Yet still efficient under the first stage in the centralized model, but its second stage performance was not ideal, hence its low ranked overall efficiency is because of bad performance in stage two. This result indicates Perlis was not efficient in distributing the water to customers. As for Labuan, it has lower scores in both standard DEA model and centralized model, hence Labuan are efficient under stage two in both years. So, Labuan needs to focus on improving the water production process only while maintaining the efficiency in water distribution process (stage 2).

\section{Conclusion}

The results of this study are in-line with Liang et al. [12] where he mentioned that in most cases of the DEA, DMUs are likely to form a multi-stage structure with intermediate measures. Hence the DEA standard model is not suitable for the situation with the multi-stage structures. This study applied the centralized model as in [12] to evaluate the performance of Malaysian water supply services in 2011 and 2012. The centralized model correspondingly has more advantages in explaining insight not available from the standard DEA model [11]-[12]. It can be concluded that the centralized model has more discriminate power in addressing a multi-stage structures situation such as water supply service operation. It also able to evaluate water supply provider's performance regarding to its water production process and also performance of water distribution processes simultaneously.

\section{Acknowledgment}

The first author acknowledges the sponsorship received from Universiti Teknologi MARA and Ministry of Higher Education, Malaysia.

\section{References}

[1] Romano, G., \& Guerrini, A. (2011). Measuring and comparing the efficiency of water utilities companies: A data envelopment analysis approach. Utilities Policy, 19, 202-209.

[2] Byrnes, P., Grosskopf, S., \& Hayes, K. (1986). Efficiency and ownership: Further evidence. Review of Economics and Statistics, 668, 337-341.

[3] Garcia-Sanchez, I. (2006). Efficiency measurement in Spanish local government: The case of municipal water services. Review of Policy Research, 23(2), 355-371.

[4] Lambert, D., Dichev, D., \& Raffiee, K. (1993). Ownership and sources of inefficiency in the provision of water services. Water Resources Research, 29, 1573-1578.

[5] Anwandter, L., \& Ozuna, T. (2002). Can public sector reform improve the efficiency of public water utilities? Environment and Development Economics, 7, 687-700.

[6] Alsharif, K., Feroz, E. H., Klemer, A., \& Raab, R. (2008). Governance of water supply systems in the Palestinian territories: a data envelopment analysis approach to the management of water resources. Journal of Environmental Management, 87, 80-94.

[7] Cook, W. D., Liang, L., \& Zhu, J. (2010). Measuring performance of two-stage network structures by DEA: A review and future perspective. Omega, 38, 423-430.

[8] Malaysian Water Association. (2013). Malaysia Water Industry Guide 2013. MWA: Kuala Lumpur.

[9] Thanassoulis, E. (2000). The use of data envelopment analysis in the regulation of UK water utilities: Water distribution. European Journal of Operational Research, 126, 436-453.

[10] Charnes, A., Cooper, W. W., \& Rhodes, E. (1978). Measuring the efficiency of decision making units. European Journal of Operational Research, 88, 525-536. 
[11] Zhu, J. (2011). Airlines performance via two-stage network DEA approach. Journal of Centrum Cathedra, $4(2), 260-269$.

[12] Liang, L., Cook, W. D., \& Zhu, J. (2008). DEA models for two-stage processes: Game approach and efficiency decomposition. Naval Research Logistics, 55, 643-653.

[13] Chen, Y., Cook, W. D., \& Zhu, J. (2010). Deriving the DEA frontier for two-stage processes. European Journal of Operational Research, 202, 138-142.

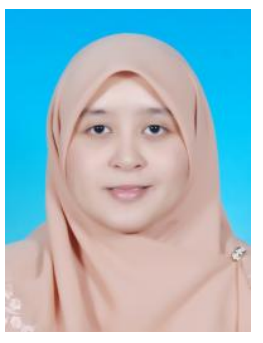

Norbaizura Kamarudin is a PhD student at the School of Mathematical Sciences, the Faculty of Science and Technology, Universiti Kebangsaan Malaysia. She received her B. Sc. in statistics and M. Sc. in management mathematics, both from Universiti Kebangsaan Malaysia. Her research interests include mathematical modeling, efficiency and data envelopment analysis.

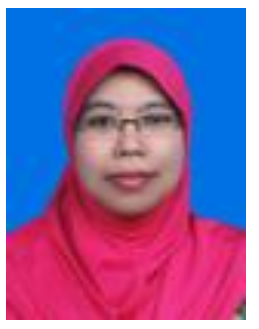

Wan Rosmanira Ismail is a senior lecturer at the School of Mathematical Sciences, the Faculty of Science and Technology, Universiti Kebangsaan Malaysia. She obtained her PhD in operational research from Loughborough University, UK in the year 2000. Her research interests include mathematical modeling, scheduling and routing, timetabling, efficiency and multi criteria decision making.

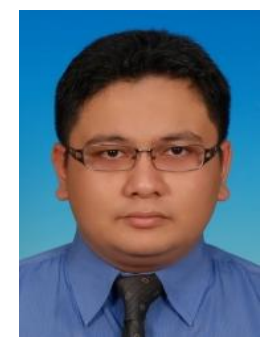

Muhammad Azri Mohd is a lecturer at Centre for Actuarial Studies, Faculty of Computer and Mathematical Sciences, Universiti Teknologi MARA. He graduated with BSc. (Hons) in actuarial science and MSc. quantitative sciences (major in financial engineering) from Universiti Teknologi MARA, Malaysia. His research focuses on performance analysis and strategies in several areas, namely finance, investment and some related operational studies on organizational issues and Islamic finance. 